This is an electronic reprint of the original article. This reprint may differ from the original in pagination and typographic detail.

Author(s): Linnavalli, Tarja; Putkinen, Vesa; Huotilainen, Minna; Tervaniemi, Mari

Title: $\quad$ Phoneme processing skills are reflected in children's MMN responses

Year: $\quad 2017$

Version:

Please cite the original version:

Linnavalli, T., Putkinen, V., Huotilainen, M., \& Tervaniemi, M. (2017). Phoneme processing skills are reflected in children's MMN responses. Neuropsychologia, 101, 76-84. https://doi.org/10.1016/j.neuropsychologia.2017.05.013

All material supplied via JYX is protected by copyright and other intellectual property rights, and duplication or sale of all or part of any of the repository collections is not permitted, except that material may be duplicated by you for your research use or educational purposes in electronic or print form. You must obtain permission for any other use. Electronic or print copies may not be offered, whether for sale or otherwise to anyone who is not an authorised user. 


\section{Author's Accepted Manuscript}

Phoneme processing skills are reflected in children's MMN responses

Tanja Linnavalli, Vesa Putkinen, Minna Huotilainen, Mari Tervaniemi

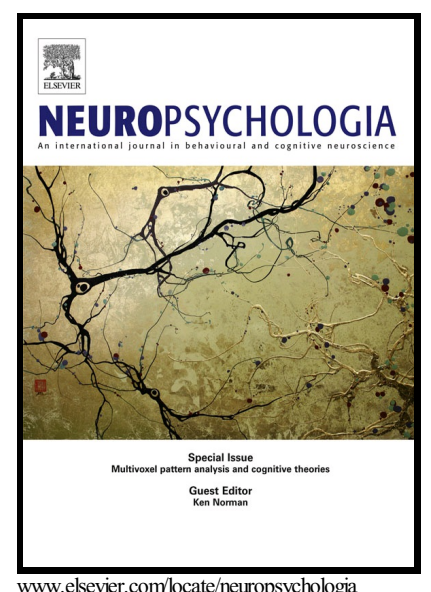

PII: $\quad$ S0028-3932(17)30179-3

DOI: $\quad$ http://dx.doi.org/10.1016/j.neuropsychologia.2017.05.013

Reference: NSY6364

To appear in: Neuropsychologia

Received date: 17 October 2016

Revised date: 13 April 2017

Accepted date: 4 May 2017

Cite this article as: Tanja Linnavalli, Vesa Putkinen, Minna Huotilainen and Mar Tervaniemi, Phoneme processing skills are reflected in children's MMI $\begin{array}{llllllllll}r & \mathrm{e} & \mathrm{s} & \mathrm{p} & \mathrm{o} & \mathrm{n} & \mathrm{s} & \mathrm{e} & \mathrm{s} & \text {, Neuropsychologic }\end{array}$ http://dx.doi.org/10.1016/j.neuropsychologia.2017.05.013

This is a PDF file of an unedited manuscript that has been accepted fo publication. As a service to our customers we are providing this early version o the manuscript. The manuscript will undergo copyediting, typesetting, an review of the resulting galley proof before it is published in its final citable form Please note that during the production process errors may be discovered whic could affect the content, and all legal disclaimers that apply to the journal pertain 


\title{
Phoneme processing skills are reflected in children's MMN responses
}

\section{Authors and affiliations}

Tanja Linnavalli ${ }^{\mathrm{a}, *}$, Vesa Putkinen ${ }^{\mathrm{a}, \mathrm{b}}$, Minna Huotilainen ${ }^{\mathrm{a}, \mathrm{c}, \mathrm{d}}$ and Mari Tervaniemi ${ }^{\mathrm{a}, \mathrm{d}}$

${ }^{\text {a }}$ Cognitive Brain Research Unit, P.O.Box 9, 00014 Helsingin yliopisto, Institute of Behavioural Sciences, University of Helsinki, Finland

${ }^{\mathrm{b}}$ Department of Music, University of Jyväskylä, Finland

${ }^{\mathrm{c}}$ Swedish Collegium for Advanced study, Uppsala University, Uppsala, Sweden

${ }^{\mathrm{d}}$ Cicero learning, Institute of Behavioural Sciences, University of Helsinki, Finland

\section{* Corresponding author}

Ms Tanja Linnavalli, Cognitive Brain Research Unit, Institute of Behavioural Sciences

P.O. Box 9, FI-00014 University of Helsinki

telephone number: +358505306476

e-mail: tanja.linnavalli@helsinki.fi

\section{Keywords}

MMN, LDN, children, behavioural tests, phoneme processing, intelligence

\begin{abstract}
Phonological awareness (PA), the core contributor in phoneme processing abilities, has a link to later reading skills in children. However, the associations between PA and neural auditory discrimination are not clear. We used event-related potential (ERP) methodology and neuropsychological testing to monitor the neurocognitive basis of phonological awareness in typically developing children. We measured 5-6-year-old children's $(\mathrm{N}=70)$ phoneme processing, word completion and perceptual reasoning skills and compared their test results to their brain responses to phonemic changes, separately for each test. We found that children performing better in Phoneme processing test showed larger mismatch negativity (MMN) responses than children scoring lower in the same test. In contrast, no correspondence between test scores and brain responses was found for Auditory closure. Thus, the results suggest that automatic auditory change detection is linked to phoneme awareness in preschool children.
\end{abstract}




\section{ACCEPTED MANUSCRIPT}

\section{Introduction}

Literacy skills are among the most crucial abilities for successful functioning in our society. Achieving them early on helps a child to do well in school and succeed in later studies. In preschool children, phonological awareness (PA), the ability to perceive and manipulate sounds in spoken language, predicts later reading skills (Kirby et al., 2003; Silvén et al., 2004). Furthermore, the success in tests investigating PA in elementary school children seems to differentiate children with average and above average reading skills (Savage et al., 2005), although it is not clear if the relationship between PA and learning to read is causal or correlational (see e.g., Castles \& Coltheart, 2004; Melby-Lervåg et al., 2012). Our knowledge of the correspondence between behavioural measures of pre-reading skills, such as phonological awareness, and neural prerequisites is still incomplete. There is much to learn about how success in neuropsychological tests manifests itself in the developing brain of children. Here we use well-established event-related potential (ERP) methodology to probe the neurocognitive basis of phonological awareness in typically developing children.

\subsection{Mismatch negativity}

Mismatch negativity (MMN) is a negative polarity component of ERPs that is thought to reflect the discrimination of change in a stream of repeating sounds (Näätänen, 1992; Winkler et al., 2009). According to the current theory, the brain predicts, i.e., forms a neural representation of the regular features in the auditory input and when a change is detected, an MMN response is elicited. MMN appears to originate from two areas: bilaterally supratemporal planes of the auditory cortices and prefrontal cortex (Näätänen \& Escera, 2000; Rinne et al., 2000). MMN occurs even when the subject is not attending to the stimuli, and this makes it a practical tool to investigate young children that are easily distracted and sometimes unmotivated to participate experimental tasks (Näätänen et 


\section{ACCEPTED MANUSCRIPT}

al., 2010; for a review, see e.g. Näätänen et al., 2007).

MMN can be recorded already in fetuses (Huotilainen et al., 2005) and newborns (Cheour et al., 2000; Kushnerenko et al., 2002; Partanen et al., 2013b; Trainor et al., 2001), and is well established in preschool (Lee et al., 2012; Lovio et al., 2009) and school-age children (Cheour et al., 2000; Datta et al., 2010; Kraus et al., 1999). With subtle deviants, MMN is small in amplitude during preschool and early school-age (Lovio et al., 2009; see e.g. Cheour, et al., 2000), gradually increasing in amplitude (Bishop et al., 2011; Putkinen et al., 2014a; Putkinen et al., 2014b). It is shown to reach adult latencies of 100-250 ms in adolescence (Paquette et al. 2013; Shafer et al., 2000; Shafer et al., 2010). MMN has been recorded in children for changes in frequency (Maurer et al., 2003; Shafer et al., 2000), phonemes (Čeponienè et al., 2004; Datta et al., 2010; Kraus et al., 1999; Kushnerenko et al., 2002; Kuuluvainen et al., 2016; Lovio et al., 2009; Lovio et al., 2010), intensity (Lovio et al., 2009; Lovio et al., 2010; Partanen et al., 2013a) and duration (Lovio et al., 2009; Lovio et al., 2010). It has also been found in children in response to more abstract features, such as changes in the direction of frequency change in sound pairs (Gumenyuk et al., 2003).

\subsection{Late discriminative negativity}

Korpilahti et al. (1995) first described the late discriminative negativity (LDN), a negative response occurring 350-550 ms after the stimulus onset. The response has been found predominately in children, both in preschool (Korpilahti et al., 2001; Korpilahti, et al., 1995; Maurer et al., 2003) and school-age (Bishop et al., 2011; Čeponienè et al., 1998; Čeponienè et al., 2002; Datta et al., 2010; Hommet et al., 2009; Korpilahti et al., 1995; Liu et al., 2014; Shafer et al., 2005; for a review, see Cheour et al., 2001). LDN appears to diminish with age and is usually absent or nearly absent in adults (Bishop et al., 2011; Hommet et al., 2009; Liu et al., 2014), although some studies have reported finding it in adults (Alho, 1992; Trejo et al., 1995). 


\section{ACCEPTED MANUSCRIPT}

In comparison with MMN, LDN seems to have distinct neural generators (Čeponienè et al., 2004; Hommet et al., 2009), and thus should not be regarded as a late manifestation of the MMN. Furthermore, unlike MMN, LDN is larger for smaller deviants (Bishop et al., 2011; Čeponienè et al., 2004). Currently, LDN is thought to reflect additional cognitive processing of subtle changes in auditory stimuli, and not to be linked to attentive or sensory processes in the brain (Bishop et al., 2011; Čeponienè et al., 1998; Datta et al., 2010; Shafer et al., 2005).

Some studies have reported LDN to be more pronounced for speech than non-speech sounds (Bishop et al., 2011; Korpilahti et al., 2001; Korpilahti et al., 1996; Kuuluvainen et al., 2016). Yet, the stimulus types in these studies have not always been acoustically comparable (Bishop et al., 2011; Korpilahti et al., 1996) and therefore the reason for differences in ERP amplitudes is not clear. There are also studies with matched stimuli that have not found any differences between linguistic and non-linguistic paradigms (Čeponienè et al., 2002; Davids et al., 2011). Overall, the functional significance of LDN response still needs clarification.

\subsection{Links between neuropsychological measures and neurophysiological indices}

Converging evidence shows that auditory ERPs and behavioural discrimination ability correspond in adults (Novitski et al., 2004; Winkler et al., 1999; for reviews, see Kujala \& Näätänen, 2010; Kujala et al., 2007) and, according to some studies, in children (Kraus et al., 1996; Maurer et al., 2003). Additionally, association between children's neurophysiological measures and their skills in speech-related tests has come up in several studies (Kujala et al., 2001; Lovio et al., 2010; Lovio et al., 2012;). For example, Lovio et al. (2010) found that 6-year-old children with familial risk for dyslexia both scored worse in phonological test and showed smaller MMNs elicited by speech sound changes than control children. Furthermore, some findings support the view that neurophysiological measures predict outcomes in speech-related tests (Hämäläinen et al., 2013; Jansson-Verkasalo et al., 2004; Kuhl et al., 2008; Maurer et al., 2009). 


\section{ACCEPTED MANUSCRIPT}

However, the association between ERPs and behavioural measures is not always straightforward and sometimes children do worse in tests than predicted from their brain responses (Bradlow et al., 1999). Thus, although it seems evident that there is a correspondence between ERP measures and linguistic test scores, the issue still needs clarification.

The relationships between intelligence measures and ERPs to auditory stimuli are largely understudied. Alternatively, the scarce literature may depend on the publication bias, since studies not finding any link between investigated measures tend not to be published. Most research seems to focus on schizophrenic (Kawakubo et al., 2006; Light \& Braff, 2005a, 2005b) or autistic patients (Weismüller et al., 2015). However, Light et al. (2007) found that the MMN response of healthy adults to duration change correlated with participants' overall level of functional status, as measured by Global Assessment of Functioning Scale (Hall, 1995). As for the children, Mikkola et al. (2007) found a correlation between MMN amplitudes to frequency changes and verbal IQ and verbal fluency test results when studying preterm and full-term children at the age of five years. In addition, when comparing children with speech disorders to typically developing children, Bauer et al. (2009) found that the amplitude of MMN correlated with the auditory memory span test results. Some studies have focused on typically developing children. Partanen et al. (2013a) discovered a connection between MMN amplitudes for intensity changes and verbal IQ tests in 4-12-year-old children. In addition, Liu et al. (2007) reported that the peak amplitudes of MMN and LDN responses of highly intelligent 11-12-year-old children for consonant change were larger and the LDN latency was shorter than those of their peers of average intelligence. As most of the studies show evidence for differences between healthy adults and groups of special features (e.g., schizophrenia patients), there is still much to be learned about associations between ERPs and intelligence measures within subject groups with no clinical background.

In our study we tested seventy typically developing children with three different tests, and thus aimed to find out whether subtle differences in neuropsychological test performance would be 


\section{ACCEPTED MANUSCRIPT}

reflected in brain responses for phonemic stimuli. Finding such differences would suggest that there are fine-tuned links between neural substrates and testable linguistic or other cognitive abilities. Our hypothesis was that children with higher scores in linguistic tests would show larger MMN and LDN responses than the children with lower scores in the same tests. We also hypothesized that children having higher scores in tests for intelligence would show larger MMN amplitudes than their lower scoring peers. If our hypotheses prove right, it would mean that in typically developing children there is a direct link between phonological awareness and/or intelligence and hearing subtle details in linguistic sounds. Furthermore, if there are differences in how discriminating different phoneme change types differentiate children with higher and lower scores in each test, we will learn more about which sound features are more closely linked to phonological awareness, or intelligence, than others.

\section{Materials and methods}

\subsection{Participants}

All 75 participants were 5-6-year old kindergarten children (mean age 5 years 9 months). Due to less than $65 \%$ accepted stimulus trials in EEG data 5 participants were excluded, and data from 70 (44 female) participants were left for further analyses. The children attended 12 different municipal Finnish language kindergartens in Espoo region, and 57 of them were native Finnish speakers. The rest were bilingual, and spoke Russian (3), Estonian (2), Albanian (4), Somali (2), Swedish (1) and Armenian (1) as their native language. Bilingual children all spoke and understood Finnish at least relatively well. Among the children were thirteen whose parents reported their children either having language problems or having close relatives with dyslexia. However, there were no official diagnoses and these children's test results [Phoneme Processing: $t(68)=.327, p=.745$; Auditory closure: $t(68)=-.614, p=.542 ;$ Perceptual Reasoning Index: $t(68)=1.522, p=.133]$ did not differ from those of the other children in the sample (for children's individual scores, see Appendix, Table 


\section{ACCEPTED MANUSCRIPT}

1). Furthermore, we conducted two rANOVAs comparing the mean amplitudes of MMN and LDN responses of children with possible language problems and the other children on nine chosen electrodes for all deviants. As we found no differences $[\mathrm{MMN}: F(1,68)=1.251, p=.283$; LDN: $F(1,68)=.500, p=.482]$, we included these children in the experiment.

The parents or guardians signed a written informed consent and the children gave their verbal assent before the experiment. The experiment protocol was approved by The Ethical Committee of the Humanities and Social and Behavioural sciences in the University of Helsinki, Finland.

\subsection{Neurocognitive assessments}

Children were tested with Phoneme processing subtest (NEPSY II, Korkman, Kirk \& Kemp, 2008), Auditory closure subtest (ITPA, Kirk et al., 1972), along with Block design and Matrix reasoning subtests (WISC-IV, Wechsler, 2010). All the tests were rehearsed according to the test guidelines with children before the experiment, and they were well understood also by the bilingual children.

Phoneme processing (PP) subtest measures phonological awareness and auditory memory. In the first section, the child sees three pictures and hears names for each object in the pictures. The experimenter pronounces then a phoneme combination that is included in one of the object names and the child has to point to the object, which the syllable belongs to. In the next section the child is asked to remove a phoneme or combination of phonemes from the uttered word and say the resulting word out loud ("Say /tak:a/, 'fireplace'. Then say the same word without /t/". The right answer is /ak:a/, 'an old woman'). In the final section, (if it is reached) the child has to replace a phoneme or combination of phonemes with given phonemes ("Say /helmi/, 'pearl'. Now say the same word but replace /i/ with /a/". The right answer is /helma/, 'hem of skirt'). Testing is stopped after six consecutive wrong answers. 


\section{ACCEPTED MANUSCRIPT}

Auditory closure (AC) test probes if a child is able to produce a complete word out of an incomplete one. It is used regularly by speech therapists in Finland and other Scandinavian countries and has been found to differentiate children with specific language impairment (SLI) from typically developing children (Hannus et al., 2013). Because of its clinical relevance, we were interested to see if $\mathrm{AC}$ has a correspondence with neurophysiological measures. The procedure of the test goes as follows: experimenter says an utterance that is incomplete as a word. Participant then has to supplement it with phonemes to make it a proper word. More than one right answer is accepted ("What word do I mean with /avai/?" Right answer might be /avain/, 'key' or /avaimet/, 'keys').

Block design and Matrix reasoning are both subtests of The Perceptual Reasoning Index's section of WISC-IV. Block design (BD) measures visuospatial skills. Children form patterns with red-and-white blocks according to a displayed model, and this performance is timed. In Matrix reasoning (MR) test children are shown an array of pictures with one missing square, and have to select from five options the picture that fits the array. This test measures fluid reasoning skills. In our study, we combined BD and MR according to instructions in WISC-IV to form Perceptual Reasoning Index (PRI) as an indication of non-verbal intelligence.

\subsection{The ERP paradigm}

The stimuli were made with semisynthetic Speech Generation Method (for details, see Alku, Tiitinen \& Näätänen, 1999) and were presented in a multifeature paradigm (Figure 1) (Näätänen et al., 2004). Unlike in traditional oddball paradigm where the deviant stimulus occurs typically 10$20 \%$ of the time, in multifeature paradigm every other stimulus is a standard and every other a deviant. In one paradigm there need to be several different deviant types that alternate so that every deviant type differs from the standard in only one feature (e.g. frequency or intensity). Thus, even though the deviants occur in $50 \%$ of the heard sounds, each deviant type appears only in e.g., $10 \%$ 


\section{ACCEPTED MANUSCRIPT}

of the stimuli. It has been shown that MMN responses of healthy adults in multifeature paradigm are similar to those elicited by traditional oddball paradigm (Pakarinen et al., 2009; Kujala, Lovio, Lepistö, Laasonen \& Näätänen, 2006). In addition, in six-year-old children's responses to five different deviant types recorded in a multifeature paradigm were comparable to those recorded in an oddball paradigm (Lovio et al., 2009). The multifeature paradigm is a very efficient way to collect a large amount of data in short time, and thus it is very convenient method to measure children. In our study, one deviant type appeared approximately in $10 \%$ of the stimuli and the actual measurements took less than 20 minutes. Had we recorded the same amount of deviant trials in an oddball paradigm with $15 \%$ of the stimuli being deviants, it would have taken more than 50 minutes to measure one subject. For a child of 5-6 years of age it is a long time to sit still. Furthermore, as the previous literature is not coherent about the phoneme change types that might or might not be linked to test performance, we wanted to include different phoneme changes in our study.

\section{**** Insert Figure 1 approximately here $* * *$}

The standard stimuli STD (P = .50) were either /pi:/ or /te:/, presented in separate blocks (Table 1). The deviant stimuli were consonant change CON $(\mathrm{P}=.10)$, vowel change VOW $(\mathrm{P}=.10)$, vowel duration change DUR $(\mathrm{P}=.10)$, intensity change INT (louder $\mathrm{P}=.05$ and softer $\mathrm{P}=.05$ ) and frequency change FRE (higher $\mathrm{P}=.05$, lower $\mathrm{P}=.05$ ). The duration of the stimuli was $170 \mathrm{~ms}$, excluding deviant DUR (100 ms). Onsets of the stimuli were $500 \mathrm{~ms}$ apart from each other. F0 was $101 \mathrm{~Hz}$ for all other stimuli expect for the FRE deviants which had the f0s of $93 \mathrm{~Hz}$ and $109 \mathrm{~Hz}$. Intensity of the stimuli was $\sim 70 \mathrm{~dB}$ (SPL) excluding the intensity deviants that were $63 \mathrm{~dB}$ and 77 dB. There were 465 stimuli in each of the four blocks and each block lasted for about 5 minutes. The order of the blocks was counterbalanced and the total EEG recording net time was 20 minutes. 


\section{ACCEPTED MANUSCRIPT}

The identical experiment paradigm has been used successfully in measuring MMN responses in both adults (Pakarinen et al., 2009) and children (Lovio et al., 2009).

Table 1 The stimuli of the multifeature paradigm. Four blocks (two blocks for each standard stimuli) were played for the participant. The blocks were in randomized order.

\begin{tabular}{cccccc}
\hline $\begin{array}{c}\text { STD } \\
\text { Standard }\end{array}$ & $\begin{array}{c}\text { VOW } \\
\text { Vowel } \\
\text { deviant }\end{array}$ & $\begin{array}{c}\text { CON } \\
\text { Consonant } \\
\text { deviant }\end{array}$ & $\begin{array}{c}\text { DUR } \\
\text { Vowel } \\
\text { duration } \\
\text { deviant }\end{array}$ & $\begin{array}{c}\text { FRE } \\
\text { Frequency } \\
\text { deviant }\end{array}$ & $\begin{array}{c}\text { INT } \\
\text { Intensity } \\
\text { deviant }\end{array}$ \\
\hline$/$ te:/ & $/$ ti:/ & $/$ pe:/ & $/$ te/ & $\pm 8 \%$ & $\pm 7 \mathrm{~dB}$ \\
\hline$/$ pi:/ & /pe:/ & $/$ ti:/ & /pi/ & $\pm 8 \%$ & $\pm 7 \mathrm{~dB}$ \\
\hline
\end{tabular}

\subsection{The procedure}

The EEG measurements and the neurocognitive tests were conducted in the kindergarten premises. The measurement rooms were as silent as possible, and only the participant and the experimenter(s) were present. EEG measurements and neurocognitive tests were conducted during the children's normal daily stay at kindergarten, on separate days. While preparing for and measuring EEG, the child watched an animated movie that was muted during measuring. The participants were asked to avoid unnecessary movement, to ignore the experimental stimuli, and to concentrate on the movie. The stimuli were presented via headphones (Sony Professional MDR-7506) with short breaks between blocks. Cookies and soft drink was offered during breaks. Preparation, measurement and removing the cap took approximately an hour, as did the neurocognitive testing.

\subsection{Data recording and processing}




\section{ACCEPTED MANUSCRIPT}

The stimuli were presented with Presentation 17.0 (Neurobehavioral Systems, Inc., CA, US) and the EEG was recorded with $32 \mathrm{Ag}-\mathrm{AgCl}$ scalp electrodes according to international 10-20 system (ActiCap; Brain Products, Germany). The EEG equipment was portable (Brainvision QuickAmp amplifier). The data were registered with sample rate of $500 \mathrm{~Hz}$ and recording reference was the average signal of all electrodes. Additional two active electrodes were placed on the mastoids behind both ears.

EEG was processed with BESA 5.3. software (MEGIS Software GmbH, Gräfelfing, Germany). Noisy electrodes were interpolated and eye blink artefacts were removed using semi-automatic Besa PCA method. Frequencies under $0.5 \mathrm{~Hz}$ and over $30 \mathrm{~Hz}$ were filtered out offline and the data were re-referenced to the mean of the mastoids. EEG was epoched from $-100 \mathrm{~ms}$ before onset to $500 \mathrm{~ms}$ after the onset of the stimuli and the epochs including amplitudes exceeding $\pm 120 \mu \mathrm{V}$ were excluded from the analyses. The responses were averaged for each participant and the averaged responses were then exported to MATLAB R2012 (The MathWorks Inc., MA, US).

The response for intensity deviant was created by averaging the responses to both intensity changes (louder and softer). In the similar way, the response for frequency deviant was created by averaging the responses to increments and decrements of frequency. The difference signals were created for each deviant stimulus by subtracting the average standard response from the average deviant responses for each participant. The standard and deviant trials from all four blocks were combined according to the stimulus category. The electrodes F3, Fz, F4, C3, Cz, C4, P3, Pz and P4 were chosen for further inspection. This is a typical choice in MMN paradigms, as it reveals frontback and left-right distribution of the brain responses. Mean amplitudes of MMN were calculated from the deviant-standard difference signal over 200-250 ms for CON, FRE, INT and VOW deviants and over 225-275 ms for DUR deviant. LDN mean amplitudes were calculated over 375-425 ms for all the deviants. The children's MMN and LDN responses typically occur in these 


\section{ACCEPTED MANUSCRIPT}

time windows and the visual inspection showed that all the inspected responses were prominent within these time ranges.

\subsection{Statistical analyses}

A three-way repeated measures ANOVA (5 deviants x 3 front-back electrode lines x 3 left-right electrode lines) was conducted with SPSS 24 (IBM Corporation, NY, USA) with three test scores (PP, AC and PRI) used as covariates and native language as between-subjects factor. Whenever sphericity could not be assumed in the analyses, Greenhouse-Geisser corrections were applied.

\section{Results}

\subsection{Test performance}

The average test results for the test scores $(P P, A C, P R I)$ are outlined in Table 2.

Table 2 Mean scores for all the tests. N=70, mean age in months (SD) 69.30 (3.1).

\begin{tabular}{lccc}
\hline Test & $\begin{array}{c}\text { Mean scores } \\
\text { (SD) }\end{array}$ & Minimum scores & Maximum scores \\
\hline Phoneme processing (PP) & $27.6(3.6)$ & 18 & 41 \\
\hline Auditory closure (AC) & $14.0(3.3)$ & 5 & 20 \\
\hline $\begin{array}{l}\text { Perceptual reasoning index } \\
(P R I)\end{array}$ & $29.4(8.1)$ & 12 & 48 \\
\hline
\end{tabular}

\subsection{Event-related potentials}

Figure 2 shows the standard and deviant responses for the combined conditions for all participants. All the responses are larger on frontal and central than parietal lines. The inspected time windows are marked with white and grey blocks. 


\section{*** Insert Figure 2 approximately here ***}

All deviants elicited MMN and LDN responses significantly differing from zero in the chosen time windows (Table 3).

Table 3 Mean MMN (225-275ms for duration deviant, 200-250ms for all the other deviants) and LDN (375-425ms) amplitudes for all children at Fz. Standard deviations in brackets.

\begin{tabular}{cll}
\hline Response & Deviant & Amplitude $(\mu \mathrm{V})$ \\
\hline MMN & Vowel & $-2.7(3.0)^{* * *}$ \\
& Consonant & $-1.1(2.4)^{* * *}$ \\
& Duration & $-4.2(3.0)^{* * *}$ \\
& Intensity & $-1.2(2.2)^{* * *}$ \\
& Frequency & $-1.8(2.9)^{* * *}$ \\
LDN & Vowel & $-5.1(3.1)^{* * *}$ \\
& Consonant & $-3.4(2.6)^{* * *}$ \\
& Duration & $-1.8(2.7)^{* * *}$ \\
& Intensity & $-3.7(2.8)^{* * *}$ \\
& Frequency & $-3.0(2.5)^{* * *}$ \\
\hline
\end{tabular}

The amplitudes significantly differing from the baseline are marked with asterisks. $* * * p<.001$

As hypothesized, the test scores in Phoneme processing had a significant main effect on the responses $[\mathrm{F}(1)=4.315 ; p=.042]$ indicating that children with higher scores on the test showed a larger MMN amplitude relative to children with lower scores (for illustrational purposes, see Appendix, Figure 1 that depicts subtraction curves for higher and lower scoring children for all three tests). Main effects of Auditory closure $[\mathrm{F}(1)=.508 ; p=.479]$ or Perceptual reasoning index $[\mathrm{F}(1)=1.700 ; p=.197]$ test scores on the responses were not significant, and neither was subjects' native language $[\mathrm{F}(1)=056 ; p=.308]$. 


\section{ACCEPTED MANUSCRIPT}

For MMN, the only significant interaction was Left-Right $\mathrm{x}$ PRI $[\mathrm{F}(2,130)=3.271 ; p=.041]$. The post hoc comparisons were conducted by comparing the estimated mean amplitudes over the left, centre and right electrode lines when PRI scores were set at the first or the third quartile. These comparisons indicated that children with higher scores did not show any lateralization of responses [with higher quartile scores (35): Left: Mean $=-2.1 \mu \mathrm{V}$; Central: Mean $=-2.0 \mu \mathrm{V}$; Right: Mean $=$ $2.1 \mu \mathrm{V}$; significance of differences between Left-Right lines: Left vs. Central $p=.596$, Left vs. Right $p=.962$, Central vs. Right $p=.581$, whereas children with lower scores showed significant rightside dominance of the responses [with lower quartile scores (24): Left: Mean $=-1.6 \mu \mathrm{V}$; Central: Mean $=-1.6 \mu \mathrm{V}$; Right: Mean $=-1.9 \mu \mathrm{V}$; significance of differences between Left-Right lines: Left vs. Central $p=.726$, Left vs. Right $p=.042$, Central vs. Right $p=.026]$. No other significant main effects of interactions were found for the MMN. Furthermore, no significant main effects or interactions were found on LDN time window.

\section{Discussion}

\subsection{Phoneme processing}

As we hypothesized, children achieving higher scores in the Phoneme Processing subtest of NEPSY II showed larger MMN amplitudes than lower performers. In other words, the children's performance in the active behavioural test was reflected in the brain responses that were measured in a passive condition. Thus, it seems that automatic auditory change detection has a link, or that it even contributes, to phonological awareness. The mechanism behind this link is subject to speculation. It could be that the change detection reflects the accuracy of the memory trace, and the more accurate it is, the easier it is to make conscious inferences and manipulations of phonemes. More research is needed to find out if the differences in automatic change detection system are innate or a consequence of different auditory environments that children live in. 


\section{ACCEPTED MANUSCRIPT}

It is especially interesting that we were not comparing typically developing children to a clinical population, as most studies have done (e.g., Kujala, 2007; Lovio et al., 2010), but the difference was seen among typically developing children. Therefore, the salience or non-salience of responses is not dependent only on the possible diagnoses in children's linguistic development, but differentiates also typically developing children from each other. Since phonological awareness is a known index of later reading skills, brain responses connected to PA might also tell us early on how the reading skills of a child are likely to develop.

Contrary to what we hypothesized, the children's LDN responses did not show differences that might be linked to their performance in phoneme processing. Thus, we found no evidence that would link the LDN response to language processing skills. Further studies are needed to assess the significance of this response that is found in children and is likely to diminish with age (Bishop et al., 2011; Hommet et al., 2009; Liu et al., 2014).

\subsection{Auditory closure}

No differences linked to Auditory closure test emerged in the children's MMN or LDN responses. As we did find significant differences in responses based in subjects' scores of Phoneme processing test, it seems that $\mathrm{AC}$ is not as strongly linked to neural sound discrimination abilities as PP. Even though the manipulation of phoneme combinations is required also in this test, $\mathrm{AC}$ may be more closely associated with vocabulary size and linguistic memory than with phonological awareness.

\subsection{Perceptual reasoning skills}

Contrary to our second hypothesis, the higher performing children in Perceptual Reasoning Index test did not show larger MMN or LDN responses to phonemic stimuli than lower performing children. Thus, based on our study, it seems that perceptual measures of intelligence do not strongly correlate with discrimination of phonemic changes. Previous findings have not been very consistent 


\section{ACCEPTED MANUSCRIPT}

as to which auditory change responses correlate with which intelligence test results; the studies have used different ERP paradigms and different tests. E.g., Light et al. (2007) found a correspondence between adults' MMN responses to duration change and overall level of functional status (Global Assessment of Functioning Scale, Hall, 1995). Both Partanen et al. (2013a) and Mikkola et al. (2007) found a link between verbal intelligence scores (WISC-IV, Wechsler, 2010; WPPSI-R, Wechsler, 1995) and responses for sound changes in children, Partanen et al. for intensity change and Mikkola et al. for frequency change. Nevertheless, the studied subjects were not comparable to each other or to the sample of the present study: Partanen et al. studied children representing very wide age distribution and Mikkola et al. compared children born preterm and full-term. As for us, we used non-verbal intelligence scores to measure children's intelligence, and phonemes as stimuli. Thus, it seems that the accuracy of auditory memory trace does not have a link to perceptual reasoning based on visual cues.

However, we found an interaction suggesting that whereas the responses of children with better perceptual reasoning skills are distributed evenly across the scalp, the responses of children not performing as well in these skills have a right side dominance. It might reflect differences in maturation - the brains of children with better perceptual reasoning skills are activated more evenly by auditory stimuli, while children with less strong performance in the same skills do show more lateralized activation. Yet, the reason for this rightward dominance is unclear. Bauer et al. (2009) found that when looking at area under the curve (AUC) of MMN, children with central auditory processing disorder (CAPD) who scored significantly lower in auditory memory span test than their peers, tended to have left-hemisphere dominance in their MMN. The control children's responses were evenly distributed. Partanen et al. (2013a) found that pre-schoolers had larger MMN responses on left and central electrodes to frequency deviant than school children, and according to Everts et al. (2009) right-lateralization of visuo-spatial processing increases by age, being more evenly distributed in young children than in older adolescents. As the literature of the correspondence 


\section{ACCEPTED MANUSCRIPT}

between intelligence measures and lateralization of brain responses is scarce and very inconsistent, more research is needed to shed light on the associations between different measures of intelligence and neurophysiological indices.

\subsection{Summary and conclusions}

The current study investigated the associations between children's performance in linguistic and cognitive tests and their neural phoneme discrimination skills. We found that children's scores in Phoneme processing test were associated with their neural auditory discrimination abilities. The children scoring higher in the test had larger MMN amplitudes to phonemic changes. Furthermore, we found that children scoring lower in Perceptual reasoning index tests showed right-side dominance in their MMN responses. Auditory closure was not correlated with neural indices in this paradigm.

Taken together, based on ERP measurements and neuropsychological testing of seventy typically developing children, it seems that automatic auditory detection is linked to phonological awareness in preschool children. Further studies are needed to investigate whether this link is correlational or causal, and whether some day it will be possible to predict individual reading skills from auditory discrimination abilities. If so, it would enable one to tailor individual training programs to improve phonological awareness prior the child is supposed to learn to read. This approach would prevent or at least minimize also the problems often occurring in parallel with slow reading skill acquisition, namely low self-esteem and social disintegration.

\section{Acknowledgements and conflict of interest}

This work was supported by graduate school of Humanities and Social Sciences, University of Helsinki; and Finnish Cultural Foundation. The authors declare no conflict of interest. The authors 


\section{ACCEPTED MANUSCRIPT}

would like to thank Tommi Makkonen and Paavo Alku for helping with technical issues and Alisa Ikonen for sharing her expert knowledge on Auditory closure speech test with us. Furthermore, we would like to thank Ida Örmä, Elina Harjunen, Hanna Ylätalo, Kristiina Tammi, Liisa Polet and Henri Pitkänen for their assistance in data collection and handling. We gratefully acknowledge the help of the numerous kindergartens, their friendly personnel and the families participating in the research. Without their enthusiasm and support this study would not have been possible.

\section{References}

Alho, K. (1992). Selective attention in auditory processing as reflected by event-related brain potentials. Psychophysiology, 29, 247-263.

Alku, P., Tiitinen, H \& Näätänen, R. (1999). A method for generating natural-sounding speech stimuli for cognitive brain research. Clinical Neurophysiology, 110, 1329-1333. http://dx.doi.org/10.1016/S1388-2457(99)00088-7

Bauer, P., Burger, M., Kummer, P. Lohscheller, J., Eyshodlt, U. \& Doellinger, M. (2009). Correlation between psychometric tests and mismatch negativity in preschool children. Folia Phoniatrica et Logopaediga, 61, 206-216. DOI: 10.1159/000227998

Bishop, D.V.M., Hardiman, M.J., \& Barry, J.G. (2011). Is auditory discrimination mature by middle childhood? A study using time-frequency analysis of mismatch responses from 7 years to adulthood. Developmental Science, 14, 402-416. DOI: 10.1111/j.1467-7687.2010.00990.x

Bradlow, A., Kraus, N., Nicol, T., McGee, T., Cunningham, J., Zecker, S. \& Carrell, T. (1999). Effects of lengthened formant transition duration on discrimination and neural representation of synthetic CV syllables by normal and reading-disabled children. Journal of Acoustic Society of America, 106(4), 2086-2096.

Castles, A. \& Coltheart, M. (2004). Is there a causal link from phonological awareness to 


\section{ACCEPTED MANUSCRIPT}

success in learning to read? Cognition, 91(1), 77-111. doi:10.1016/S0010-0277(03)00164-1

Čeponienè, R., Cheour, M. \& Näätänen, R. (1998). Interstimulus interval and auditory eventrelated potentials in children: evidence for multiple generators. Electroencephalography and Clinical Neurophysiology, 108, 345-354. http://dx.doi.org/10.1016/S0168-5597(97)00081-6

Čeponienè, R., Lepistö, T., Soininen, M., Aronen, E., Alku, P. \& Näätänen, R. (2004). Eventrelated potentials associated with sound discrimination versus novelty detection in children. Psychophysiology, 42, 130-141. DOI: 10.1111/j.1469-8986.2003.00138.x

Čeponienè, R., Yaguchi, K., Shestakova, A., Alku, P., Suominen, K. \& Näätänen, R. (2002). Sound complexity and 'speechness' effects on pre-attentive auditory discrimination in children. International Journal of Psychophysiology, 43, 199-211. http://dx.doi.org/10.1016/S01678760(01)00172-6

Cheour, M., Korpilahti, P., Martynova, O. \& Lang, A.-H. (2001). Mismatch negativity and late discriminative negativity in investigating speech perception and learning in children and infants. Audiology \& Neuro-Otology, 6, 2-11. DOI:10.1159/000046804

Cheour, M., Leppänen, P. \& Kraus, N. (2000). Mismatch negativity (MMN) as a tool for investigating auditory discrimination and sensory memory in infants and children. Clinical Neurophysiology, 111, 4-16. http://dx.doi.org/10.1016/S1388-2457(99)00191-1

Datta, H., Shafer, V., Morr, M., Kurtzberg, D. \& Schwartz, R. (2010). Electrophysiological indices of discrimination of long-duration, phonetically similar vowels in children with typical and atypical language development. Journal of Speech, Language and Hearing Research, 53, 757-777.

Davids, N., Segers, E., van den Brink, B., Mitterer, H., van Balkom, H., Hagoort, P. \& Verhoeven, L. (2011). The nature of auditory discrimination problems in children with specific language impairment: An MMN study. Neuropsychologia, 49, 19-28. doi:10.1016/j.neuropsychologia.2010.11.001 


\section{ACCEPTED MANUSCRIPT}

Everts, R., Lidzba, K., Wilke, M., Kiefer, C., Mordasini, M., Schroth, G., Perrig, W. \& Steinlin, M. (2009). Strenghtening of laterality of verbal and visuospatial functions during childhood and adolescence. Human Brain Mapping, 30, 473-483.

Gumenyuk, V., Korzyukov, O., Alho, K., Winkler, I., Paavilainen, P. \& Näätänen, R. (2003).

Electric brain responses indicate preattentive processing of abstract acoustic regularities in children. NeuroReport, 14, 1411-1415.

Hall, R. (1995). Global assessment of functioning. A modified scale. Psychosomatics, 36, $267-275$.

Hannus, S., Kauppila, T., Pitkäniemi, J. \& Launonen, K. (2013). Use of language tests when identifying specific language impairment in primary health care. Folia Phoniatrica et Logopaediga, 65, 40-46. DOI: 10.1159/000350318

Hommet, C., Vidal, J., Roux, S., Blanc, R., Barthez, M-A., De Becque, B., Barthelemy, C., Bruneau, N. \& Gomot, M. (2009). Topography of syllable change-detection electrophysiological indices in children and adults with reading disabilities. Neuropsychologia, 47, 761-770. doi:10.1016/j.neuropsychologia.2008.12.010

Huotilainen, M., Kujala, A., Hotakainen, M., Parkkonen, L., Taulu, S., Simola, J., Nenonen, J., Karjalainen, M. \& Näätänen, R. (2005). Short-term memory functions of the human fetus recorded with magnetoencephalography. Neuroreport, 16(1), 81-84.

Hämäläinen, J.A., Guttorm, T.K., Richardson, U., Alku, P., Lyytinen, H., \& Leppänen, P.H.T. (2013). Auditory event-related potentials measured in kindergarten predict later reading problems at school age. Developmental Neuropsychology, 38, 550-566.

http://dx.doi.org/10.1080/87565641.2012.718817

Jansson-Verkasalo, E., Korpilahti, P., Jäntti, V., Valkama, M., Vainionpää, L., Alku, P., Suominen, K. \& Näätänen, R. (2004). Neurophysiologic correlates of deficient phonological 


\section{ACCEPTED MANUSCRIPT}

representations and object naming in prematurely born children. Clinical Neurophysiology, 115, 179-187. doi:10.1016/S1388-2457(03)00319-5

Kawakubo, Y., Kasai, K., Kudo, N., Rogers, M., Nakagome, K., Itoh, K. \& Kato, N. (2006). Phonetic mismatch negativity predicts verbal memory deficits in schizophrenia. Neuroreport, 17(10), 1043-1046. DOI: 10.1097/01.wnr.0000221828.10846.ba

Kirby, J. R., Parrila, R. K. \& Pfeiffer, S. L. (2003). Naming speed and phonological awareness as predictors of reading development. Journal of Educational Psychology, 95, 453-464. DOI: $10.1037 / 0022-0663.95 .3 .453$

Kirk, S., McCarthy, J. \& Kirk, W. (1972). ITPA:n teoria, ominaisuudet ja käyttö. Jyväskylän yliopisto, Jyväskylä.

Korkman, M., Kirk, U. \& Kemp, S.L. (2008). Nepsy II - lasten neuropsykologinen tutkimus. 1st edition. Psykologien Kustannus Oy, Helsinki.

Korpilahti, P., Krause, C., Holopainen, I. \& Lang, H. (2001). Early and late mismatch negativity elicited by words and speech-like stimuli in children. Brain and Language, 76, 332-339. http://dx.doi.org/10.1006/brln.2000.2426

Korpilahti, P., Krause, C.M. and Lang, A.H. (1996). Automatic auditory word perception in children: Part I, Event-related potentials (ERPs). In: Electrophysiological correlates of auditory perception in normal and language impaired children. Thesis by Korpilahti, P., a, University of Turku, Turku, Finland.

Korpilahti, P., Lang, H. \& Aaltonen, O. (1995). Is there a late latency mismatch negativity (MMN) component? Electroencephalography and Clinical Neurophysiology, 95, 96.

Kraus, N., Koch, D., McGee, T., Nicol, T. \& Cunningham, J. (1999). Speech-sound discrimination in school-age children: psychophysical and neurophysiologic measures. Journal of Speech, Language and Hearing Research, 42(5), 1042-1060. 


\section{ACCEPTED MANUSCRIPT}

Kraus, N., McGee, J., Carrell, T., Zecker, S., Nicol, T. \& Koch, D. (1996). Auditory

neurophysiologic response and discrimination deficits in children with learning problems. Science, 273, 971-3. DOI: 10.1126/science.273.5277.971

Kuhl, P.K., Conboy, B.T., Coffey-Corina, S., Padden, D., Rivera-Gaxiola, M., \& Nelson, T. (2008). Phonetic learning as a pathway to language: new data and native language magnet theory expanded (NLMe). Philosophical Transactions of the Royal Society B, 363, 979-1000. doi:10.1098/rstb.2007.2154

Kujala, T. (2007). The role of early auditory discrimination deficits in language disorders. Journal of Psychophysiology, 21(3-4), 239-250. DOI 10.1027/0269-8803.21.34.239

Kujala, T., Karma, K., Čeponiene, R., Belitz, S., Turkkila, P., Tervaniemi, M. \& Näätänen, R. (2001). Plastic neural changes and reading improvement caused by audio- visual training in reading-impaired children. Proceedings of the National Academy of Sciences of the United States of America, 98, 10509-10514. doi:10.1073/pnas.181589198

Kujala, T., Lovio, R., Lepistö, T., Laasonen, M. \& Näätänen, R. (2006). Evaluation of multiattribute auditory discrimination in dyslexia with the mismatch negativity. Clinical Neurophysiology, 117, 885-893.

Kujala, T. \& Näätänen, R. (2010). The adaptive brain: A neurophysiological perspective. Progress in Neurobiology, 91(1), 55-67. doi:10.1016/j.pneurobio.2010.01.006

Kujala, T., Tervaniemi, M. \& Schröger, E. (2007). The mismatch negativity in cognitive and clinical neuroscience: Theoretical and methodological considerations. Biological Psychology, 74(1), 1-19. doi:10.1016/j.biopsycho.2006.06.001

Kuuluvainen, S., Alku, P., Makkonen, T., Lipsanen, J. \& Kujala, T. (2016). Cortical speech and non-speech discrimination in relation to cognitive measures in preschool children. European Journal of Neuroscience, 1-13. doi:10.1111/ejn.13141. 


\section{ACCEPTED MANUSCRIPT}

Kushnerenko, E., Čeponienè, R., Balan, P., Fellman, V. \& Näätänen, R. (2002). Maturation of the auditory change detection response in infants: a longitudinal ERP study. Brain Imaging, 13(15), $1843-1848$.

Lee, C.-Y., Yen, H., Yeh, P., Lin, W.-H., Cheng, Y.-Y., Tzeng, Y.-L. \& Wu, H.-C. (2012).

Mismatch responses to lexical tone, initial consonant, and vowel in Mandarin-speaking

preschoolers. Neuropsychologia, 50, 3228-3239.

http://dx.doi.org/10.1016/j.neuropsychologia.2012.08.025

Light, G. \& Braff, D. (2005a). Mismatch negativity deficits are associated with poor functioning in schizophrenia patients. Archives of General Psychiatry, 62, 127-136.

doi:10.1001/archpsyc.62.2.127

Light, G. \& Braff, D. (2005b). Stability of mismatch negativity deficits and their relationship to functional impairments in chronic schizophrenia. American Journal of Psychiatry, 162, 1741-1743.

Light, G., Swerdlow, N. \& Braff, D. (2007). Preattentive sensory processing as indexed by the MMN and P3a brain responses in associated with cognitive and psychosocial functioning in healthy adults. Journal of Cognitive neuroscience, 19(10), 1624-1632. doi: 10.1162/jocn.2007.19.10.1624

Liu, H-M., Chen, Y. \& Tsao, F-M. (2014). Developmental changes in mismatch responses to Mandarin consonants and lexical tones from early to middle childhood. PLoS ONE, 9(4); e95587. doi:10.1371/journal.pone.0095587.

Liu, T., Shi, J., Zhang, Q., Zhao, D., \& Yang, J. (2007). Neural mechanisms of auditory sensory processing in children with high intelligence. Neuroreport, 18(15), 1571-1575. DOI:

10.1097/WNR.0b013e3282ef7640

Lovio, R., Halttunen, A., Lyytinen, H., Näätänen, R., \& Kujala, T. (2012) Reading skill and neural processing accuracy improvement after a 3-hour intervention in preschoolers with difficulties in reading related skills. Brain Research, 1448, 42-55. doi:10.1016/j.brainres.2012.01.071 


\section{ACCEPTED MANUSCRIPT}

Lovio, R., Näätänen, R. \& Kujala, T. (2010). Abnormal pattern of cortical speech feature discrimination in 6-year-old children at risk for dyslexia. Brain Research, 1335, 53-62. doi:10.1016/j.brainres.2010.03.097

Lovio, R., Pakarinen, S., Huotilainen, M., Alku, P., Silvennoinen, S., Näätänen, R. \& Kujala, T. (2009) Auditory discrimination profiles of speech sound changes in 6-year-old children as determined with the multi-feature MMN paradigm. Clinical Neurophysiology, 120, 916-921. doi:10.1016/j.clinph.2009.03.010

Marie, C., Kujala, T. \& Besson, M. (2012). Musical and linguistic expertise influence preattentive and attentive processing of non-speech sounds. Cortex, 47, 447-457. doi:10.1016/j.cortex.2010.11.006

Maurer, U., Bucher, K., Brem, S., Benz, R., Kranz, F., Schulz, E., van der Mark, S., Steinhausen, H.-C., \& Brandeis, D. (2009). Neurophysiology in Preschool Improves Behavioral Prediction of Reading Ability Throughout Primary School. Biological Psychiatry, 66, 341-348. doi:10.1016/j.biopsych.2009.02.031

Maurer, U., Bucher, K., Brem, S. \& Brandeis, D. (2003). Altered responses to tone and phoneme mismatch in kindergartners at familial dyslexia risk. NeuroReport, 14(17), 2245-2250. doi:10.1016/S1388-2457(03)00032-4

Melby-Lervåg, M., Lyster, S.-A. H., \& Hulme, C. (2012). Phonological skills and their role in learning to read: A Meta-Analytic Review. Psychological Bulletin, 138(2), 322-352. doi:

\section{$10.1037 / \mathrm{a} 0026744$}

Mikkola, K., Kushnerenko, E., Partanen, E., Serenius-Sirve, S., Leipälä, J., Huotilainen, M. \& Fellman, V. (2007). Auditory event-related potentials and cognitive function of preterm children at five years of age. Clinical Neurophysiology, 118, 1494-1502. doi:10.1016/j.clinph.2007.04.012 


\section{ACCEPTED MANUSCRIPT}

Novitski, N., Tervaniemi, M., Huotilainen, M. \& Näätänen, R. (2004). Frequency discrimination at different frequency levels as indexed by electrophysiological and behavioral measures. Cognitive Brain Research, 20, 26-36. doi:10.1016/j.cogbrainres.2003.12.011

Näätänen, R. (1992). Attention and brain function. Hillsdale, NJ: Erlbaum.

Näätänen, R., Astikainen, P., Ruusuvirta, T. \& Huotilainen, M. (2010). Automatic auditory intelligence: An expression of the sensory-cognitive core of cognitive processes. Brain Research Reviews, 64, 123-136. doi:10.1016/j.brainresrev.2010.03.001

Näätänen, R. \& Escera, C. (2000). Mismatch negativity: clinical and other applications. Audiology and Neurotology, 5, 105-110. DOI:10.1159/000013874

Näätänen, R., Paavilainen, P., Rinne, T., \& Alho, K. (2007). The mismatch negativity (MMN) in basic research of central auditory processing: A review. Clinical Neurophysiology, 118, 2544-2590. doi:10.1016/j.clinph.2007.04.026

Pakarinen, S., Lovio, R., Huotilainen, M., Alku, P., Näätänen, R. \& Kujala, T. (2009). Fast multi-feature paradigm for recording several mismatch negativities (MMNs) to phonetic and acoustic changes in speech sounds. Biological Psychology, 82, 219-226. doi:10.1016/j.biopsycho.2009.07.008

Paquette, N., Vannasing, P., Lefrançois, M., Lefebvre, F., Roy, M.-S., McKerral, M., Lepore, F., Lassonde, M., \& Gallagher, A. (2013). Neurophysiological Correlates of Auditory and Language Development: A Mismatch Negativity Study. Developmental Neuropsychology, 38, 386-401. http://dx.doi.org/10.1080/87565641.2013.805218

Partanen, E., Torppa, R., Pykäläinen, J., Kujala, T. \& Huotilainen, M. (2013a). Children’s brain responses to sound changes in pseudo words in a multifeature paradigm. Clinical Neurophysiology, 124, 1132-1138. http://dx.doi.org/10.1016/j.clinph.2012.12.005 


\section{ACCEPTED MANUSCRIPT}

Partanen, E., Pakarinen, S., Kujala, T. \& Huotilainen, M. (2013b). Infants' brain responses for speech sound changes in fast multifeature MMN paradigm. Clinical Neurophysiology, 124, 1578-1585. http://dx.doi.org/10.1016/j.clinph.2013.02.014

Putkinen, V., Tervaniemi, M., Saarikivi, K., de Vent, N., \& Huotilainen, M. (2014a). Investigating the effects of musical training on functional brain development with a novel Melodic MMN paradigm. Neurobiology of Learning and Memory, 110, 8-15. doi:10.1016/j.nlm.2014.01.007.

Putkinen, V., Tervaniemi, M., Saarikivi, K., Ojala, P., \& Huotilainen, M. (2014b). Enhanced development of auditory change detection in musically trained school-aged children: a longitudinal event-related potential study. Developmental Science, 17(2), 282-297. doi:10.1111/desc.12109.

Rinne, T., Alho, K., Ilmoniemi, R. J., Virtanen, J. \& Näätänen, R. (2000). Separate time behaviors of the temporal and frontal mismatch negativity sources. Neuroimage, 12, 14-19. doi:10.1006/nimg.2000.0591

Savage, R. S., Frederickson, N., Goodwin, R., Patni, U., Smith, N. \& Tuersley, L. (2005). Relationships among rapid digit naming, phonological processing, motor automaticity, and speech perception in poor, average, and good readers and spellers. Journal of Learning Disabilities, 38, $12-28$.

Shafer, V., Morr, M., Datta, H., Kurtzberg, D. \& Schwartz, R. (2005). Neurophysiological indexes of speech processing deficits in children with specific language disorder. Journal of Cognitive Neuroscience, 17, 1168-1180. doi: 10.1162/0898929054475217

Shafer, V., Morr, M., Kreuzer, J. \& Kurtzberg, D. (2000). Maturation of mismatch negativity in school-age children. Ear and hearing, 21(3), 242-251.

Shafer, V.L., Yu, Y.H., \& Datta, H. (2010). Maturation of speech discrimination in 4- to 7-yr-old children as indexed by event-related potential mismatch responses. Ear and Hearing, 31, 735-745. DOI: 10.1097/AUD.0b013e3181e5d1a7 


\section{ACCEPTED MANUSCRIPT}

Silvén, M., Poskiparta, E. \& Niemi, P. (2004). The odds of becoming a precocious reader of Finnish. Journal of Educational Psychology, 96, 152-164. DOI: 10.1037/0022-0663.96.1.152

Tervaniemi, M., Jacobsen, T., Röttger, S., Kujala, T., Widmann, A., Vainio, M., Näätänen, R. \& Schröger, E. (2006). Selective tuning of cortical sound-feature processing by language experience. European Journal of Neuroscience, 23, 2538-41. doi:10.1111/j.1460-9568.2006.04752.x

Trainor, L., Samuel, S., Desjardins, R. \& Sonnadara, R. (2001). Measuring temporal resolution in infants using mismatch negativity. NeuroReport, 12(11), 2443-2448.

Trejo, L., Ryan-Jones, D. \& Kramer, A. (1995). Attentional modulation of the mismatch negativity elicited by frequency differences between binaurally presented tone bursts. Psychophysiology, 32, 319-328.

Weissmüller, B., Thienel, R., Youlden, A-M., Fulham, R., Koch, M. \& Schall, U. (2015). Psychophysiological correlates of developmental changes in healthy and autistic boys. Journal of Autism and Developmental Disorders, 45, 2168-2175. DOI 10.1007/s10803-015-2385-x

Wechsler D. (1995). WPPSI-R. Wechsler Preschool and Primary Scale of Intelligence-Revised. Psykologien kustannus Oy, Helsinki.

Wechsler, D. (2010). WISC-IV. Wechsler Intelligence Scale For Children - IV. NCS Pearson, Ltd. Psykologien Kustannus Oy, Helsinki.

Winkler, I., Denham, S. L., \& Nelken, I. (2009). Modeling the auditory scene: predictive regularity representations and perceptual objects. Trends in Cognitive Sciences, 13(12), 532-540. http://dx.doi.org/10.1016/j.tics.2009.09.003

Winkler, I., Kujala, T., Tiitinen, H., Sivonen, P., Alku, P., Lehtokoski, A., Czigler, I., Csépe, V., Ilmoniemi, R.J., \& Näätänen, R. (1999). Brain responses reveal the learning of foreign language phonemes. Psychophysiology, 36, 638-642. 
Figure $1-$ single column

Multi-feature paradigm

$\begin{array}{lllllllllllll}S & D_{4} & S & D_{5} & S & D_{1} & S & D_{4} & S & D_{2} & S & D_{3} & \ldots\end{array}$

Time

S - standard stimulus

D - deviant stimulus

Figure 1 Schematic illustration of the multifeature paradigm. $D_{1}-D_{5}$ stand for different deviant types used in the paradigm. 


\section{ACCEPTED MANUSCRIPT}

Figure $2-2$ columns, colour for both print and online

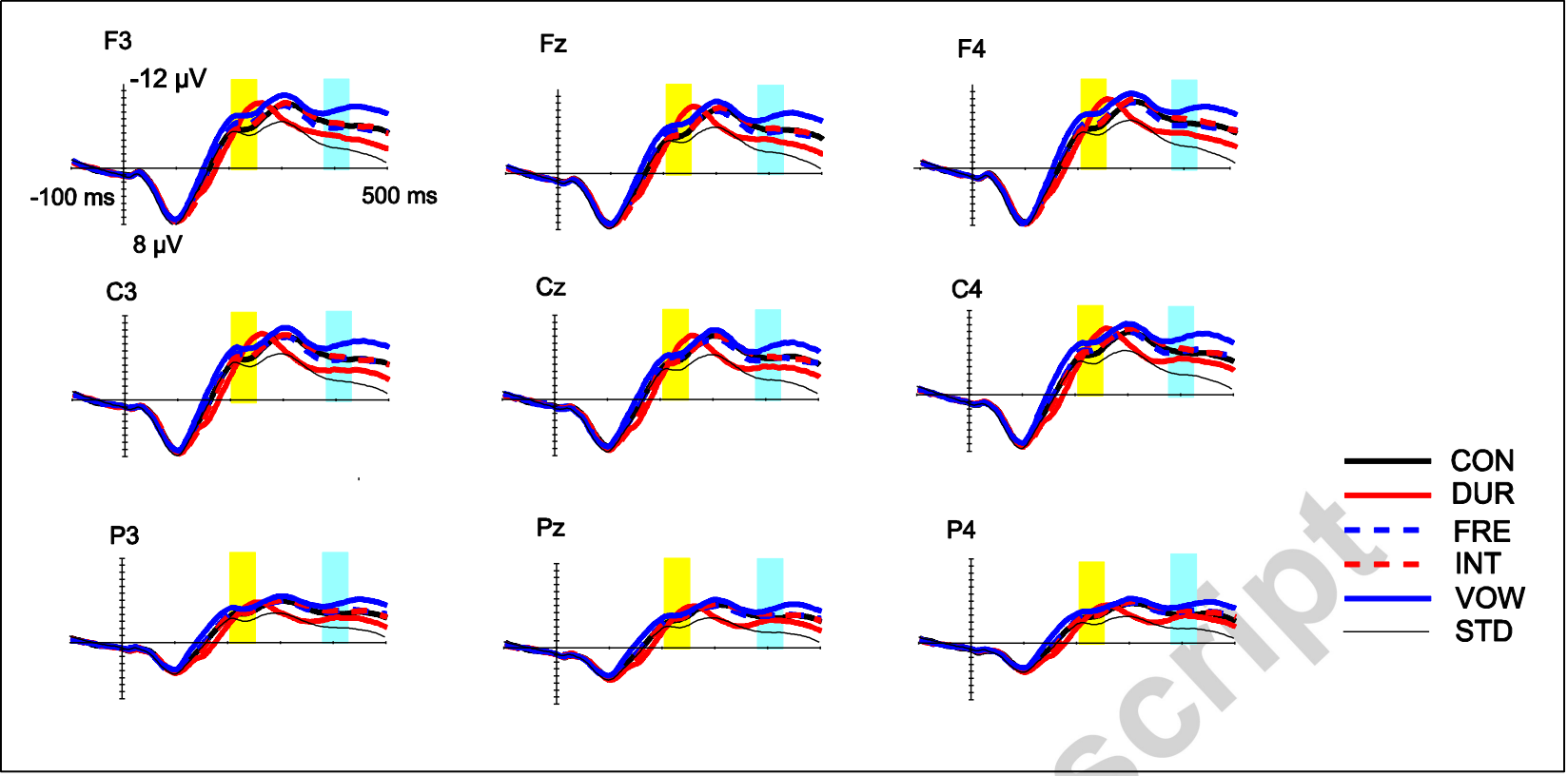

Figure 2 Standard and deviant responses for combined conditions for all participants. Yellow blocks show the inspected MMN (200-250 ms) time window for Vowel, Intensity, Frequency and Consonant deviants (the MMN time window for Duration was chosen between 225-275ms). Blue blocks show the inspected LDN (375-425 ms) time windows for all deviants.

Table 1 Individual scores for all the tests. LP stands for children whose parents reported them having language problems or their close relatives having dyslexia and NLP for children whose parents did not report any problems.

\begin{tabular}{llccc}
\hline Subject & \multicolumn{3}{c}{ Scores } \\
\cline { 2 - 5 } & & Phoneme Processing & Auditory Closure & $\begin{array}{c}\text { Perceptual Reasoning } \\
\text { Index }\end{array}$ \\
& & (Mean 27.6; SD 3.6) & (Mean 14.0; SD 3.3) & (Mean 29.4; SD 8.1) \\
\hline 01 & LP & 24 & 16 & 22.5 \\
\hline 05 & LP & 25 & 16 & 28.5 \\
\hline 10 & LP & 25 & 13 & 27.0 \\
\hline 12 & LP & 26 & 13 & 18.0 \\
\hline 14 & LP & 32 & 14 & 49.5 \\
\hline 17 & LP & 27 & 13 & 45.0 \\
\hline 19 & LP & 33 & 13 & 45.0 \\
\hline 25 & LP & 25 & 13 & \\
\hline
\end{tabular}




\section{ACCEPTED MANUSCRIPT}

\begin{tabular}{|c|c|c|c|c|}
\hline 39 & LP & 28 & 14 & 28.5 \\
\hline 42 & LP & 30 & 17 & 31.5 \\
\hline 43 & LP & 32 & 11 & 48.0 \\
\hline 57 & LP & 29 & 15 & 46.5 \\
\hline 72 & LP & 27 & 7 & 21.0 \\
\hline 03 & NLP & 24 & 19 & 30.0 \\
\hline 04 & NLP & 32 & 20 & 22.5 \\
\hline 06 & NLP & 29 & 17 & 36.0 \\
\hline 07 & NLP & 25 & 11 & 12.0 \\
\hline 09 & NLP & 33 & 18 & 34.5 \\
\hline 11 & NLP & 34 & 15 & 39.0 \\
\hline 13 & NLP & 26 & 13 & 22.5 \\
\hline 15 & NLP & 24 & 15 & 34,5 \\
\hline 16 & NLP & 27 & 14 & 33.0 \\
\hline 18 & NLP & 29 & 17 & 25.5 \\
\hline 21 & NLP & 27 & 18 & 21.0 \\
\hline 22 & NLP & 31 & 17 & 27.0 \\
\hline 23 & NLP & 30 & 19 & 37.5 \\
\hline 24 & NLP & 25 & 14 & 12.0 \\
\hline 27 & NLP & 24 & 13 & 33.0 \\
\hline 28 & NLP & 26 & 12 & 33.0 \\
\hline 30 & NLP & 26 & 19 & 39.0 \\
\hline 32 & NLP & 29 & 18 & 36.0 \\
\hline 33 & NLP & 26 & 14 & 22.5 \\
\hline 34 & NLP & 27 & 13 & 30.0 \\
\hline 35 & NLP & 30 & 15 & 30.0 \\
\hline 36 & NLP & 25 & 16 & 28.5 \\
\hline 37 & NLP & 25 & 14 & 21.0 \\
\hline 38 & NLP & 26 & 18 & 39.0 \\
\hline 40 & NLP & 28 & 19 & 36.0 \\
\hline 41 & NLP & 29 & 14 & 36.0 \\
\hline 44 & NLP & 24 & 13 & 28.5 \\
\hline 48 & NLP & 26 & 11 & 27.0 \\
\hline 49 & NLP & 30 & 8 & 22.5 \\
\hline 50 & NLP & 28 & 15 & 27.0 \\
\hline 52 & NLP & 26 & 12 & 24.0 \\
\hline 54 & NLP & 41 & 14 & 27.0 \\
\hline 55 & NLP & 28 & 14 & 27.0 \\
\hline 56 & NLP & 22 & 14 & 24.0 \\
\hline 58 & NLP & 26 & 6 & 36.0 \\
\hline 59 & NLP & 25 & 13 & 25.5 \\
\hline 60 & NLP & 29 & 15 & 30.0 \\
\hline 61 & NLP & 28 & 17 & 25.5 \\
\hline 62 & NLP & 39 & 19 & 46.5 \\
\hline 63 & NLP & 30 & 12 & 30.0 \\
\hline 64 & NLP & 27 & 18 & 24.0 \\
\hline 65 & NLP & 27 & 16 & 24.0 \\
\hline 66 & NLP & 25 & 14 & 21.0 \\
\hline 67 & NLP & 33 & 17 & 30.0 \\
\hline 68 & NLP & 28 & 12 & 28.5 \\
\hline 70 & NLP & 26 & 14 & 28.5 \\
\hline 71 & NLP & 26 & 7 & 33.0 \\
\hline 73 & NLP & 26 & 11 & 22.5 \\
\hline
\end{tabular}




\begin{tabular}{lllcl}
\multicolumn{5}{c}{ ACCEPTED MANUSCRIPT } \\
\hline 74 & NLP & 26 & 5 & 24.0 \\
\hline 75 & NLP & 30 & 12 & 21.0 \\
\hline 76 & NLP & 29 & 15 & 16.5 \\
\hline 78 & NLP & 30 & 13 & 30.0 \\
\hline 80 & NLP & 23 & 9 & 16.5 \\
\hline 81 & NLP & 24 & 7 & 45.0 \\
\hline 82 & NLP & 28 & 14 & 37.5 \\
\hline 83 & NLP & 18 & 10 & 30.0 \\
\hline 84 & NLP & 26 & 14 & 30.0 \\
\hline
\end{tabular}

Phoneme processing
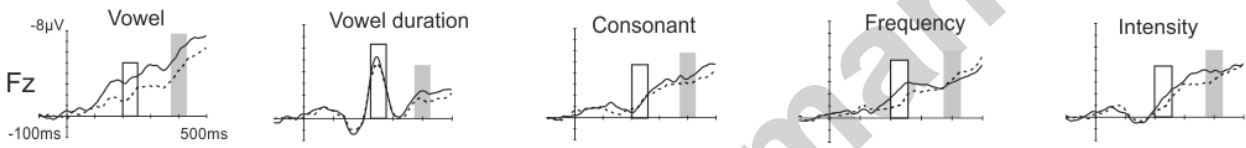

Auditory closure
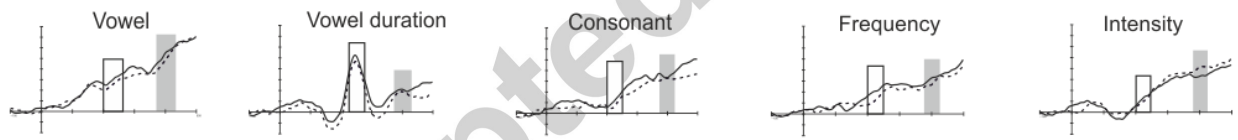

Perceptual reasoning index
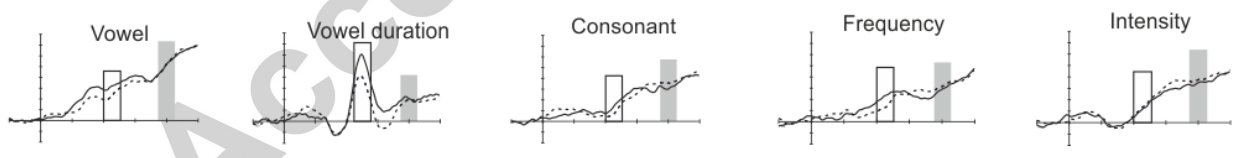

Higher scoring group Lower scoring group

Figure 1 Averaged subtraction waveforms at Fz electrode for higher and lower scoring groups in each test, for all deviants. The groups were divided based on median scores of the tests. Top: both Phoneme processing groups' responses at Fz electrode and the averaged distributions of responses during the MMN and LDN time windows for all deviants $\left(N_{\text {high }}=31, N_{\text {low }}=39\right)$. Middle: both 


\section{ACCEPTED MANUSCRIPT}

Auditory closure groups' responses at Fz electrode and the averaged distributions of responses during the MMN and LDN time windows for all deviants $\left(N_{\text {high }}=28, N_{\text {low }}=42\right)$. Bottom: both Perceptual reasoning index groups' responses at Fz electrode and the averaged distributions of responses during the $M M N$ and LDN time windows for all deviants $\left(N_{\text {high }}=33, N_{\text {low }}=37\right)$. White blocks mark the inspected MMN and grey blocks the inspected LDN time windows.

\section{Research highlights:}

- Behavioural and ERP data were collected from 70 typically developing children.

- Better phoneme processing skills were associated with larger MMN responses.

- No correspondence between intelligence measures and MMN or LDN responses was found. 